\title{
Mechanisms promoting upriver transport of larvae of two fish species in the Hudson River estuary
}

\author{
Eric T. Schultz ${ }^{1, *}$, Kamazima M. M. Lwiza ${ }^{2}$, Megan C. Fencil ${ }^{1,3}$, Jennifer M. Martin ${ }^{1,4}$ \\ ${ }^{1}$ Department of Ecology and Evolutionary Biology, University of Connecticut, 75 North Eagleville Road, Storrs, \\ Connecticut 06269-3043, USA \\ ${ }^{2}$ Marine Sciences Research Center, State University of New York, Stony Brook, New York 11794-5000, USA \\ ${ }^{3}$ Present address: The University of Texas at Austin, Marine Science Institute, 750 Channel View Drive, Port Aransas, \\ Texas 78373-5015, USA \\ ${ }^{4}$ Present address: Center for Quantitative Fisheries Ecology, Old Dominion University, Norfolk, Virginia 23529, USA
}

\begin{abstract}
Bay anchovy Anchoa mitchilli and naked goby Gobiosoma bosc larvae have been reported to move up-estuary. In the present study, we examined depth preferences and periodic vertical movements that might promote such along-estuary transport in these 2 species. We conducted 2 cruises of $3 \mathrm{~d}$ each in the Hudson River estuary, USA. The cruises were 1 wk apart, coinciding with spring and neap tides. We sampled every $2 \mathrm{~h}$ with an ichthyoplankton trawl to permit tests of time, depth, and lateral position on larval concentration. We also collected data on water-column structure with a CTD, and current velocity with an acoustic Doppler current profiler (ADCP). We briefly sampled at several sites over a distance of $25 \mathrm{~km}$ along the river, and found that larvae of both species were uniformly abundant along this section although salinity decreased sharply with increasing distance upriver. Bay anchovy larvae were more abundant than goby larvae (median concentration 234 vs 6.6 ind. $100 \mathrm{~m}^{-3}$ ). Most sampling was conducted at an oligohaline location (mean salinity $=3$ to $5 \mathrm{psu}$ ). Larvae were typically more concentrated at greater depths; among anchovy larvae during neap tide conditions, and goby larvae during neap and spring tide conditions, larvae were more concentrated at 6 and $8 \mathrm{~m}$ than at the surface by a factor of 2 to 9 . Large larvae showed a stronger depth preference than small larvae. During spring tide, the water column was less stratified, and anchovy larvae under these conditions were uniformly distributed vertically. There were slight lateral differences in larval concentration, with fewer larvae in shallow water over the shoals than in similar depths in the main channel. We evaluated periodic cycles in flow and larval distributions via harmonic regression. Tidal constituents of the depth-averaged current flow included the $\mathrm{K} 1($ period $=23.9 \mathrm{~h}), \mathrm{M} 2($ period $=12.4 \mathrm{~h})$, and the M4 (period $=6.2 \mathrm{~h})$ tides. Harmonic regression explained $>95 \%$ of the observed variability in mean flow. Diel periodicity in depth-averaged larvae concentration was evident, particularly among large anchovy and goby larvae during neap tide conditions. Larvae were more abundant in the sampled depths at night than during the day by a factor of 3 to 10 . There was also diel periodicity in the mean depth of goby larvae, such that larvae were about $2 \mathrm{~m}$ shallower at night than during the day. There was no periodic variability in the mean depth of anchovy larvae. We suggest that diel periodicity in larval concentration and mean depth reflects diel migration to shallower water at night, noting that temporal variability in net avoidance may also contribute to the periodicity. We conclude that anchovy and goby larvae exhibit a depth distribution and vertical migration behavior that promotes upriver transport. Transport should be most rapid during neap tide periods.
\end{abstract}

KEY WORDS: Estuaries $\cdot$ Selective tidal-stream transport $\cdot$ Fish larvae $\cdot$ Engraulidae $\cdot$ Gobiidae

\section{INTRODUCTION}

Many species of meroplankton, including larvae of marine and anadromous fishes, concentrate in estuaries, where there is high productivity and possibly refuge from predation (Day et al. 1989). The spatial distribution of these organisms is shaped by estuarine flow, population-level processes such as mortality, and individual-level processes such as adult spawning and larval behavior. Attention has particularly focused on 
how larval behaviors, especially depth preferences and periodic vertical movements, may promote up-estuary advection or at least retention in the estuary despite mean seaward flow. We are conducting ongoing research on the larval bay anchovy Anchoa mitchilli and the naked goby Gobiosoma bosc in the Hudson River estuary with the ultimate goal of predicting along-estuary movements of larvae based on knowledge of larval behavior and estuarine dynamics. In this study we examined larval depth preferences and vertical migration patterns.

Efforts to build predictive models of larval distribution must consider several important influences on along-estuary movement. Previous work has focused on larval depth distribution; because estuarine flow has relatively high vertical shear, along-estuary advection will be sensitive to vertical position. Up-estuary transport is promoted by larval preference for deeper water, possibly in combination with a migration into shallower waters during flood tides (referred to as selective tidal stream transport: reviews by Norcross \& Shaw 1984 and Boehlert \& Mundy 1988; recent findings include those of Rowe \& Epifanio 1994, Yamashita et al. 1996, Forward et al. 1999, Jager 1999, Welch et al. 1999, and Grioche et al. 2000). Diel vertical migration can also influence advection (Hill 1991). The potential impact of lateral position should be evaluated (e.g. Weinstein et al. 1980, Melville-Smith et al. 1981, Holt et al. 1989, Forward et al. 1999), because alongriver flow can have pronounced lateral variability, depending on bathymetry and mixing (Wong 1994, Valle-Levinson \& Lwiza 1995, Kasai et al. 2000). Ontogenetic effects on larval depth distributions and migration must also be considered (Fortier \& Leggett 1983, Holt et al. 1989, Laprise \& Dodson 1989, Rowe \& Epifanio 1994). Sensory faculties and swimming capabilities change dramatically during larval development, and may be expected to affect the distribution of larvae in the water column. A factor that seems to have been generally overlooked in studies of estuarine transport is the impact of the spring-neap tidal cycle on vertical mixing. It is well known that stratification tends to break down during spring tide conditions because of turbulent mixing (Webb \& D'Elia 1980, Geyer 1995, Peters 1997). Stratification of larvae that is engendered by depth preference or a habit of vertical migration may relax under these conditions as well.

Larval bay anchovy and naked goby are apparently retained in estuaries, and possibly advected upestuary, but how this distribution comes about is poorly understood. The bay anchovy is an estuarine-marine species. After overwintering in waters of the continental shelf, adult anchovy concentrate inshore to spawn in estuaries (Vouglitois et al. 1987), with peak spawning occurring in mesohaline water of 13 to $15 \mathrm{psu}$
(Dovel 1971, 1981). Larvae and young juveniles are extremely abundant in eastern North American estuaries (McHugh 1967) and play an important role in food-web dynamics in these systems (Baird \& Ulanowicz 1989). Young-of-the-year Anchoa mitchilli are common in low-salinity waters up-estuary from regions where spawning occurs, suggesting that young anchovy have some means of directed transport (Dovel 1981, Loos \& Perry 1991, Kimura et al. 2000). The naked goby Gobiosoma bosc is an estuarine-resident fish, whose eggs are attached to the inside of hinged oyster shells and guarded by males (Wang \& Kernehan 1979). After hatching, the larvae move upriver until they reach 12 to $15 \mathrm{~mm}$ in length and settle to a benthic habitat (Massman et al. 1963, Shenker et al. 1983).

There has been 1 previous effort to determine whether periodic vertical movements and/or depth preferences promote along-estuary transport of larval bay anchovy in the Hudson River estuary (Schultz et al. 2000). That study was designed to account for both local short-term changes (i.e. within a flood-ebb tidal cycle) in the vertical distribution of larvae, as well as along-river changes in distribution over longer timescales (i.e. weeks), using a single research vessel. It was evident that the $12.5 \mathrm{~h}$ periods of sampling at any one location were too brief to accurately characterize local temporal influences on larval abundance.

The study reported herein incorporated several significant modifications from the previous work. The present study was designed with longer intervals of vessel-based continuous sampling at a single site in the oligohaline portion of the river, where larval abundance is high. The high abundance of larvae and the rarity of eggs in this portion of the river and further upriver (Haverstraw Bay: see Dovel 1981, Schmidt 1992, Schultz et al. 2000) indicates that transport of larvae is likely. We timed the 2 sampling intervals (roughly $3 \mathrm{~d}$ each) to coincide with spring and neap tidal phases. We sampled larvae in specific depth layers in the main channel and over the shoals on each side of the river. We included brief intervals of sampling at sites upriver and downriver of our main site to enable us to characterize the along-river gradient in larval concentration. Along-river gradients can have a pronounced effect on local fluctuations in larval abundance, as water is driven back and forth along the river in tidal excursions (Fortier \& Leggett 1983, Schultz et al. 2000). We also tested whether spatial and temporal influences on larval concentration vary ontogenetically. In addition to the predictions regarding depth effects and tidal effects, we hypothesized that there would be lateral differences in concentration (coinciding with lateral shifts in tidal flow) and ontogenetic change, reflecting the greater swimming abilities of larger larvae. Sampling also included detailed current 
profiling. We present a summary of the temporal variability in flow here, so that the periodicity in larval distribution can be referenced to tidal flow. In future reports the larval data will be combined with a more detailed flow characterization to project the rate of along-river larval transport.

\section{MATERIALS AND METHODS}

The sampling program was designed to furnish information on temporal variability in larval anchovy concentrations, water-column structure, and depthspecific flow at a single site on the river. Two cruises were conducted from the RV 'Onrust' (State University of New York). The first cruise (Cruise 1998-C1; abbreviated henceforth as Cruise 1) lasted about $3 \mathrm{~d}$, and the second (Cruise 1998-C2: Cruise 2) about $3.5 \mathrm{~d}$, with a 2.5 d gap between cruises. The first cruise was conducted during a spring tide, and the second cruise during a neap tide.

We sampled multiple sites along the river, and multiple stations within each site (Fig. 1, Tables 1 \& 2). We sampled a cross-river transect at each site. Along each transect, we conducted biological and physical sampling at 3 stations: Stn W near the west end of the transect, over the shoal; Stn C near the mid-point of the transect and in the deepest part of the shipping channel; Stn E, the east end of the transect, over the shoal.

We concentrated our sampling on 1 main transect ('Main'), with rapid surveys of other transects (Upriver-1, Upriver-2, and Downriver: Fig. 1) at the beginning and end of the sampling period. The along-river distance between Downriver and Upriver- 2 is $24.9 \mathrm{~km}$. On the upand down river transects, we completed single sets of ichthyoplankton samples, and deployed a CTD (General Oceanics; dates and times of samples in Table 1). Along the Main transect, ichthyoplankton and CTD sampling was interspersed with sampling of water flow. Every $2 \mathrm{~h}$, we completed the full series of station visits (W, C, and E), each of which consisted of an ichthyoplankton tow and a CTD deployment. When a sequence of station casts was complete, we cruised back and forth along the transect, collecting velocity field data from an acoustic Doppler current profiler (ADCP; $600 \mathrm{kHz}$ model, RD Instruments). The ADCP was set to a sampling interval of $30 \mathrm{~s}$ with $0.5 \mathrm{~m}$ depth bins.

Ichthyoplankton sampling was depth-stratified at each station. The net used was a $1 \mathrm{~m}^{2}$ Tucker trawl (Research Nets), equipped with 4 nets of a $333 \mu \mathrm{m}$ mesh, each net with a 7:1 length to width ratio to minimize leading pressure waves. The trawl had a release mechanism that relayed depth information to a deck box/computer interface, and was fitted with a temperature probe and conductivity sensor, thus providing a backup CTD device. At Stns W and E only a single $2 \mathrm{~m}$ depth bin (1 to $3 \mathrm{~m}$ ) was sampled. At Stn C we sampled 4 depth bins (9 to 7,7 to 5,5 to 3,3 to $1 \mathrm{~m}$ ). We remained above the bottom to avoid snagging the net. The portion of the water column that was not sampled varied among stations and also with the tide, since bottom depth varied with tidal stage. On the Main transect during maximum flood tide the deepest $4 \mathrm{~m}$ of the channel station was not sampled, while during maximum ebb tide the deepest $2 \mathrm{~m}$ was not sampled. The net was deployed in such a way that the deepest bin was sampled first and shallower bins were sampled in succession (about $3 \mathrm{~min}$ for each net). We towed the

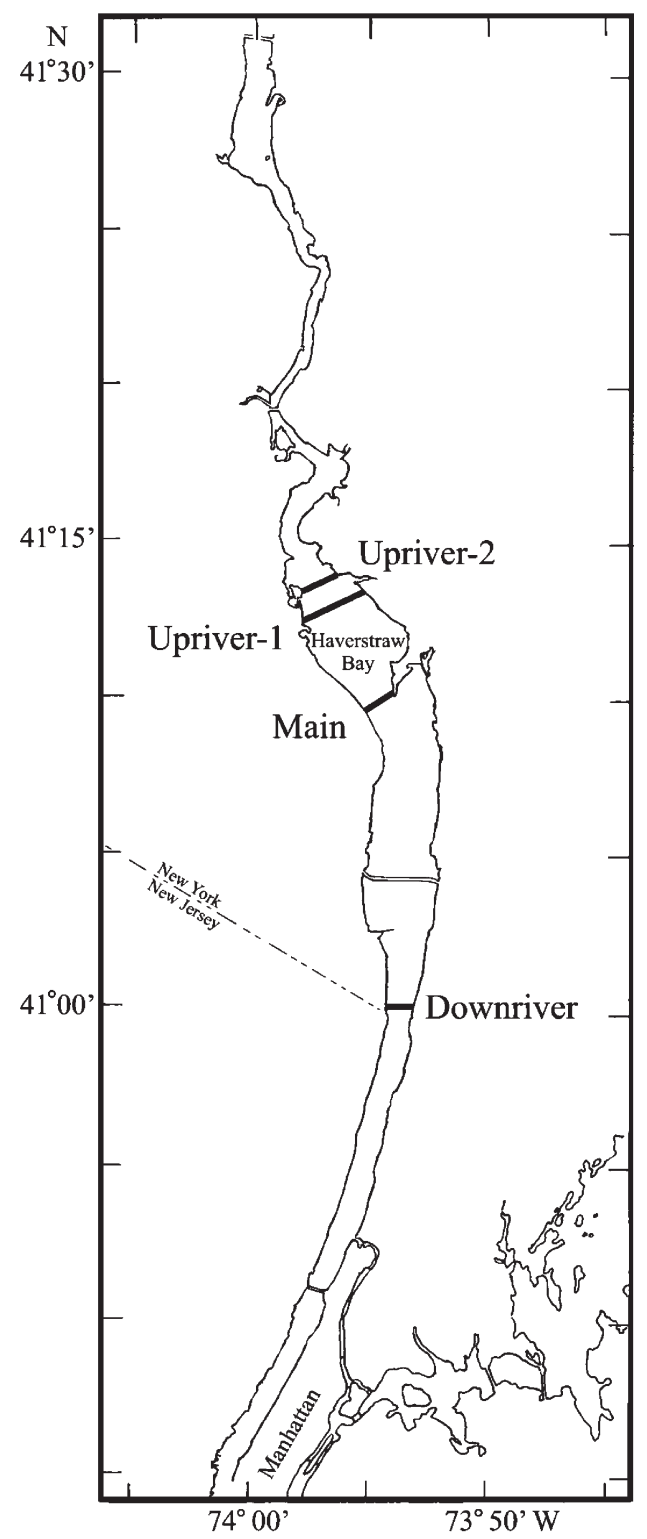

Fig. 1. Map of stations occupied in summer of 1998. Feature crossing the river between Downriver and Main transects is the Tappan Zee Bridge 
Table 1. Schedule of cruises, summer 1998. For each cruise, the spring/neap tide stage, and the times of occupation of each transect, are listed

\begin{tabular}{|c|c|c|c|c|c|}
\hline Cruise & $\mathrm{M}_{\mathrm{f}}$ tide stage & Downriver & Main & Upriver-1 & Upriver-2 \\
\hline Cruise 1 & Spring & 23 July 09:00 h & $\begin{array}{l}23 \text { July 15:00 h- } \\
26 \text { July 06:00 h }\end{array}$ & 23 July 13:00 h & \\
\hline Cruise 2 & Neap & 31 July 23:00 h & $\begin{array}{l}28 \text { July } 18: 00 \mathrm{~h}- \\
31 \text { July } 18: 00 \mathrm{~h}\end{array}$ & & 31 July 20:00 h \\
\hline
\end{tabular}

Table 2. Locations and sample sizes of biological and physical sampling. The entries for each transect (Downriver, Main, Upriver-1, Upriver-2) include the location (in terms of $\mathrm{km}$ along the main stem from the river mouth), and the number of completed transits of the transect. For each station on the transect (W: west; C: channel; E: east), depth (in m, taken during high water at Main and during the tide coinciding with the first transit on the other transects), and position in map coordinates are listed

\begin{tabular}{|c|c|c|c|c|}
\hline & Downriver & Main & Upriver-1 & Upriver-2 \\
\hline River km & 37 & 55 & 60 & 62 \\
\hline Cruise 1 transits & 1 & 32 & 1 & \\
\hline Cruise 2 transits & 1 & 35 & & 1 \\
\hline Cruise 1 mean salinity & 7.4 & 3.0 & 3.0 & \\
\hline Cruise 2 mean salinity & 15 & 5.1 & & 4.9 \\
\hline $\begin{array}{ll}\text { Stn W: Depth } \\
\text { Location }\end{array}$ & $\begin{array}{c}4 \\
41.001^{\circ} \mathrm{N}, 73.961^{\circ} \mathrm{W}\end{array}$ & $\begin{array}{c}10 \\
41.161^{\circ} \mathrm{N}, 73.916^{\circ} \mathrm{W}\end{array}$ & $\begin{array}{c}6 \\
41.202^{\circ} \mathrm{N}, 73.951^{\circ} \mathrm{W}\end{array}$ & $\begin{array}{c}10 \\
41.225^{\circ} \mathrm{N}, 73.961^{\circ} \mathrm{W}\end{array}$ \\
\hline $\begin{array}{ll}\text { Stn C: } & \text { Depth } \\
& \text { Location }\end{array}$ & $\begin{array}{c}16 \\
41.000^{\circ} \mathrm{N}, 73.894^{\circ} \mathrm{W}\end{array}$ & $\begin{array}{c}13 \\
41.164^{\circ} \mathrm{N}, 73.911^{\circ} \mathrm{W}\end{array}$ & $\begin{array}{c}8 \\
41.199^{\circ} \mathrm{N}, 73.942^{\circ} \mathrm{W}\end{array}$ & $\begin{array}{c}13 \\
41.227^{\circ} \mathrm{N}, 73.956^{\circ} \mathrm{W}\end{array}$ \\
\hline $\begin{array}{ll}\text { Stn E: } & \text { Depth } \\
& \text { Location }\end{array}$ & $\begin{array}{c}8 \\
41.000^{\circ} \mathrm{N}, 73.887^{\circ} \mathrm{W}\end{array}$ & $\begin{array}{c}8 \\
41.168^{\circ} \mathrm{N}, 73.904^{\circ} \mathrm{W}\end{array}$ & $\begin{array}{c}4 \\
41.203^{\circ} \mathrm{N}, 73.936^{\circ} \mathrm{W}\end{array}$ & $\begin{array}{c}9 \\
41.229^{\circ} \mathrm{N}, 73.949^{\circ} \mathrm{W}\end{array}$ \\
\hline
\end{tabular}

net in an along-river direction. Flow-meter readings were used to estimate sample volume, which was on average $133 \mathrm{~m}^{3}$ per net. Once the trawl was retrieved, the ichthyoplankton samples were preserved in ethanol.

Larvae were identified and counted. Samples appearing to have $>500$ anchovy larvae were split for enumeration, but the entire samples were used for enumeration of goby larvae. Larval counts for each sample were converted to concentration estimates (ind. per $100 \mathrm{~m}^{3}$ ). For statistical analysis, concentration was transformed as $\log _{10}($ concentration +1$)$. We made no corrections for escapement.

Larval lengths were measured for up to 50 individuals selected randomly from each sample. If fewer than 50 individuals were in the sample, we measured them all. We measured larvae smaller than ca. $18 \mathrm{~mm}$ using an image-analysis system (Optimas Version 6.1) configured to interface with a dissecting microscope at $8 \times$ magnification (actual magnification on the computer monitor: $15 \times$ ). Larger larvae were measured with calipers to the nearest $0.1 \mathrm{~mm}$. The abundance of each size class of larvae was estimated by multiplying a column vector containing size-class frequencies in the measured subsample by the total concentration of larvae in the sample. Length data in the present paper are uncorrected for shrinkage.

We conducted analyses of mean salinity among the different sites along the river, and mean salinity as a function of depth at Main. Salinity profiles were averaged in $2 \mathrm{~m}$ depth bins, to correspond to larval sampling. Analysis of the CTD data from the second cruise suggested that the instrument was malfunctioning. We therefore used data from the sensor on the Tucker Trawl release mechanism for the second cruise.

We conducted a principal components analysis (PCA) to simplify analysis of ontogenetic changes in behavior and distribution. The size-class limits we used differed between species (Anchoa mitchilli: $\leq 8$, 10, 12, 14, and $\geq 16 \mathrm{~mm}$; Gobiosoma bosc: $\leq 4,5,6$, and $7 \mathrm{~mm}$ ). PCA was conducted on the covariance matrix of abundance-by-size among samples. The eigenvectors of the component axes that explained a significant amount of variation in the dataset (up to $80 \%$ of the total variation) summarized variation in abundanceby-size. We conducted separate analyses for each cruise, so that the differences in size among samples in an analysis would not be magnified by seasonal size increases. We grouped larvae into 2 sizes (small and large) as the result of this analysis (see 'Results'). 
We evaluated along-river patterns of salinity and larvae, and the lateral and vertical distribution pattern of salinity and larvae at Main. Along-river patterns were evaluated as a 1-way analysis of variance, treating transect location as a classification variable. For the analysis of salinity and larvae at Main, the depth-station combination was treated as a classification variable with 6 levels ('bins': Stns E, W, C; with 4 depths at C), and size of larvae was treated as a 2-level classification. Salinity patterns were tested in a 1-way analysis of variance. Larval distribution patterns were tested initially as a 2 -way analysis of variance. In the event that the distribution across bins differed between size classes (i.e. significant size $\times$ bin interaction), we conducted separate tests of the bin effect on each size class; otherwise we tested for a bin effect on total concentration of larvae.

We used harmonic regression (Bliss 1958, McLellan 1965, Batschelet 1979) to fit periodic changes in current velocity, larval concentration, and mean larval depth at the Main transect. Analyses of temporal variability were confined to the channel samples. To identify the periodic changes in current velocity, we conducted harmonic regression on the mean current velocity over the water column. To identify the periodic changes in larval abundance and distribution, we conducted harmonic regression on 2 summary variables: (1) larval concentration, as the mean over all 4 depth bins for each tow; (2) mean depth of larvae (formula in Appendix 1). Mean larval concentration changes periodically to the extent that larvae migrate into and out of the depth range sampled by our trawl (and also changes with avoidance behavior: see 'Discussion'). Mean depth changes periodically to the extent that vertical migration affects the depth distribution within the depth range sampled by our trawl. Either variable alone, or both variables, will change periodically if there is vertical migration of larvae.

The statistical model tested for day-to-day changes and 3 tidal constituents: K1, M2, and M4 (Time periods $=23.9,12.4$, and $6.2 \mathrm{~h}$, respectively; Pugh 1987). Appendix 2 (regression model construction) describes how periodic variables were formulated. We evaluated the contribution of the M6 component (time period = $4.1 \mathrm{~h}$ ) in preliminary analyses, but subsequently eliminated it because it had no explanatory power. Separate analyses were conducted for each cruise. Day-to-day changes were included in the regression models using 2 variables representing first-order (date, in seconds) and second-order $\left(\right.$ date $\left.^{2}\right)$ effects. Collinearity between these 2 variables was eliminated by centering date (i.e. by standardizing as the difference from the mean time of the cruise) before date ${ }^{2}$ was calculated. In these short time series, K1 tidal constituent effects and diel effects (time period $=24 \mathrm{~h}$ ) have been aliased, and we have treated the K1 effects on larval concentration and depth as representative of day/night changes. We report the estimates of slope for the day-to-day changes, and amplitude and phase angle for the tidal constituents, if they were nominally significant $(p<0.05)$ based on Student's $t$-tests. We have also corrected for overestimates of significance stemming from multiple testing via a stepwise Bonferroni procedure (Rice 1989).

We tested for an association between current velocity and larval catch features, as predicted by the selective tidal-stream transport model. We tested for an effect of current on both larval abundance and mean depth, in each case via bivariate regression; alongchannel current velocity was the predictor.

Statistical analyses were conducted using Proc GLM and Proc Reg in PC-SAS (Release 8.0, running in Microsoft Windows Version 4.0.95; (C) SAS Institute, and Microsoft Corporation).

\section{RESULTS}

A total of 71 ichthyoplankton transects were conducted (Table 2). Bay anchovy larvae were present in all samples; the median concentration of anchovy larvae was 234 individuals $100 \mathrm{~m}^{-3}$ (Fig. 2A). The frequency distribution of larval concentration conformed to a lognormal distribution, and ranged over 1 order of magnitude. Gobies were much less abundant; the median concentration of goby larvae was 6.6 individuals $100 \mathrm{~m}^{-3}$ (Fig. 2C). Almost $20 \%$ of the samples contained no goby larvae. Both anchovy larvae and goby larvae were more abundant on Cruise 1 than Cruise 2 (Fig. 3A,B). We collected anchovy eggs only at Downriver during each cruise (data not shown). No goby eggs were found in any sample.

There were pronounced along-river patterns in salinity, but not in larval concentration. Salinity was substantially higher at Downriver than further upriver (Table 2). Anchovy larvae were slightly more abundant at Main than on the other transects, during both cruises (Fig. 3A). The transect effect on anchovy larval concentration was not significant during either cruise. Goby larval abundance decreased slightly upriver during the first cruise, but during the second cruise was about as high at Upriver-2 as at Downriver. The difference in goby larval abundance among transects was not significant during Cruise 1. The difference in goby larval abundance among transects was significant in Cruise 2 (1-way analysis of variance, $F_{2,226}=4.7, \mathrm{p}=0.01$ ), but was small relative to other sources of variance $\left(R^{2}=0.04\right)$.

\section{Size distribution}

Samples varied in larval size distribution as well as larval concentration. Over all transects, mean anchovy 

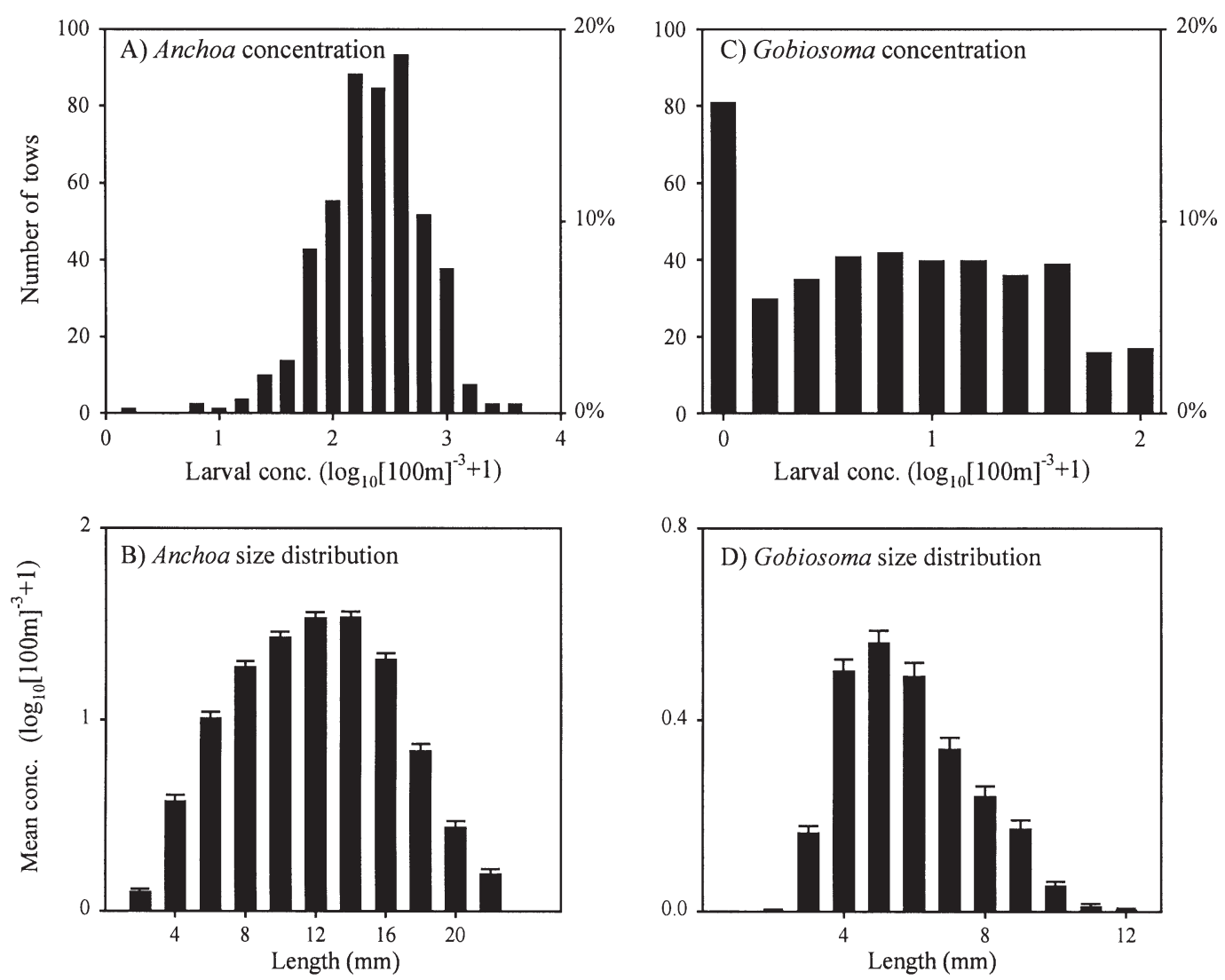

Fig. 2. Anchoa mitchilli and Gobiosoma bosc. Top: catch distribution of (A) anchovy, and (C) goby larvae. Bottom: size distribution of (B) anchovy, and (D) goby larvae (mean \pm SD of the concentration of each 2 mm size class)

length was $12.1 \mathrm{~mm}(\mathrm{SD}=3.2$; Fig. $2 \mathrm{~B})$ and mean goby length was $5.8 \mathrm{~mm}(\mathrm{SD}=0.9$; Fig. 2D). We analyzed variability among samples in abundance-at-size via PCA (Table 3). The first principal axis in each species-cruise combination described differences among samples in the concentration of larvae across all size classes (note positive loadings for all size classes on PC1), explaining most of the multivariate variance (Table 3A: Anchoa mitchilli, 53 and 58\% for Cruises 1 and 2 respectively; Table 3B: Gobiosoma bosc, 66\% for both cruises). Additional variance components were associated with variability in size distribution; the second principal axis comprised positive coefficients for small size classes and negative coefficients for large size classes, or vice versa. The variability in size distribution is not identifiable with a single size class, as would be indicated by a single divergent loading value. We elected to partition the abundance-at-size data into 2 relatively inclusive groups, small (A. mitchilli up to $11 \mathrm{~mm}, G$. bosc up to $5 \mathrm{~mm}$ ) and large (A. mitchilli $13 \mathrm{~mm}$ and larger, G. bosc $5 \mathrm{~mm}$ and larger).

Anchoa mitchilli size classes were distributed along the river identically in the first cruise, but not the sec- ond. In the first cruise, mean size along each transect ranged from 11.3 to $12.1 \mathrm{~mm}$. The concentration of small and large larvae varied among transects in the same way (2-way analysis of variance: effect of size $\times$ transect interaction on concentration, $F_{2,372}=0.18, \mathrm{p}=$ $0.84)$. In the second cruise, larvae averaged $12 \mathrm{~mm}$ on Main, but averaged $14 \mathrm{~mm}$ on the other transects. There was a significant difference between the size groups in their among-transect distribution in Cruise 2 (effect of size $\times$ transect interaction on concentration, $F_{2,446}=5.0, \mathrm{p}=0.007$ ), with low concentrations of small larvae at Downriver (Fig. 3C). Among small, but not large, larvae, concentration varied among transects (1-way analysis of variance; small: $F_{2,223}=9.0, \mathrm{p}=$ 0.0002 ; large: $F_{2,223}=0.32, \mathrm{p}=0.72$ ).

Gobiosoma bosc size classes were distributed along the river identically in each cruise. Mean larval size declined slightly upriver in each cruise (Cruise 1: mean length $=5.6,4.9$, and $5.9 \mathrm{~mm}$ at Downriver, Main and Upriver-1 respectively; Cruise 2: 6.6, 6.0 and $5.6 \mathrm{~mm}$ ). There was no difference between the size-groups in their among-transect distribution in either cruise (effect of size $\times$ transect interaction on concentration, Cruise 1 : $F_{2,278}=0.66, \mathrm{p}=0.52 ;$ Cruise $\left.2: F_{2,348}=1.4, \mathrm{p}=0.26\right)$. 

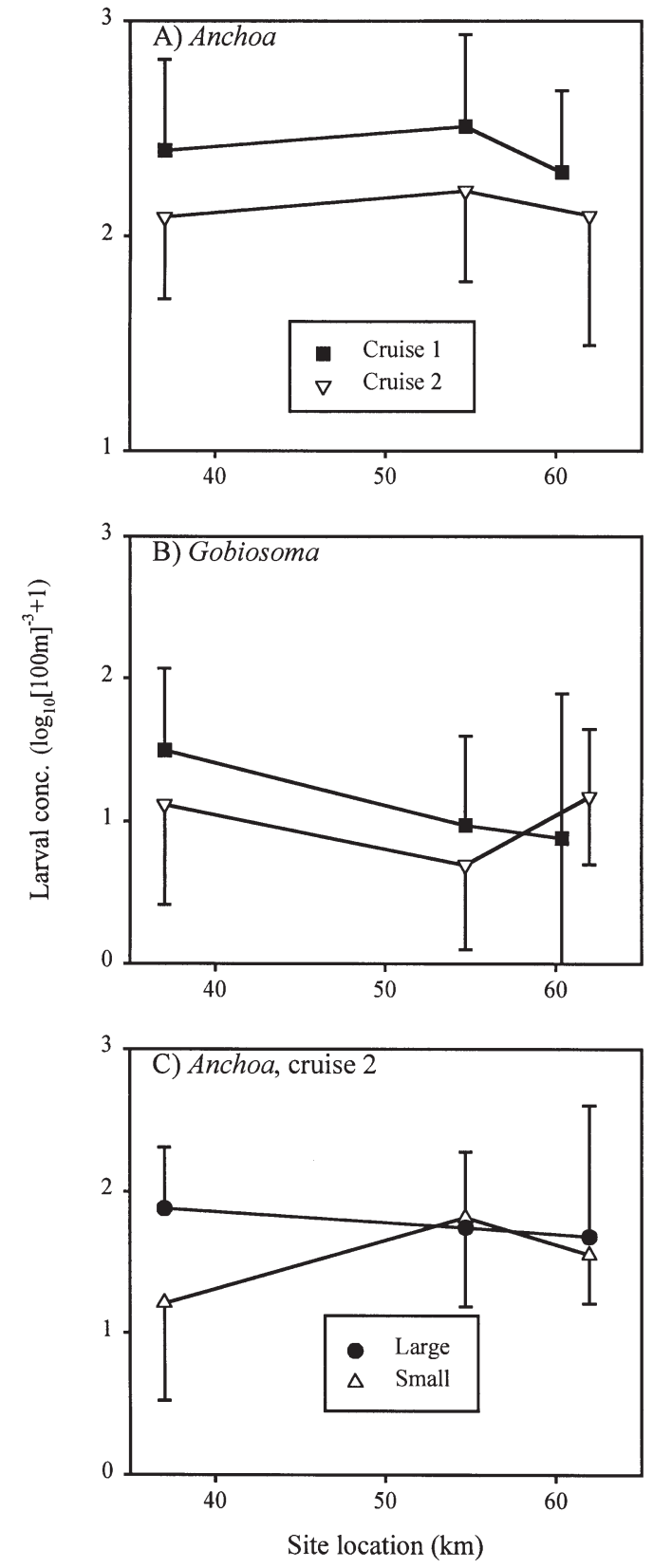

Fig. 3. Anchoa mitchilli and Gobiosoma bosc. Along-river variability in larval concentration (means + SD). (A) Anchovy larval concentration as a function of location for Cruises 1 and 2. (B) Goby larval concentration as a function of location for Cruises 1 and 2; symbols as in (A). (C) Anchovy larval concentration as a function of size group during Cruise 2

\section{Lateral and vertical distribution of salinity and larvae}

Salinity was greater at greater depths on both cruises (Fig. 4). As expected, the vertical structure of salinity was less pronounced during the spring tide conditions of Cruise 1 than during the neap tide conditions of Cruise 2. There were significant differences
Table 3. Anchoa mitchilli and Gobiosoma bosc. Principal components analysis (PCA) of concentration-at-size data. For the first 2 principal component axes (PC1, PC2), the proportion of the total variance explained, $\mathrm{p}(\mathrm{var})$, and the loadings of each larval size class are listed

\begin{tabular}{|c|c|c|c|c|c|c|}
\hline \multicolumn{7}{|c|}{ (A) Anchoa mitchilli } \\
\hline Axis & & $8 \mathrm{~mm}$ & $10 \mathrm{~mm}$ & $12 \mathrm{~mm}$ & $14 \mathrm{~mm}$ & $16 \mathrm{~mm}$ \\
\hline \multicolumn{7}{|c|}{ Cruise 1} \\
\hline PC1 & 0.53 & 0.45 & 0.51 & 0.45 & 0.45 & 0.36 \\
\hline PC2 & 0.27 & -0.40 & -0.33 & -0.08 & 0.19 & 0.83 \\
\hline \multicolumn{7}{|c|}{ Cruise 2} \\
\hline PC1 & 0.58 & 0.34 & 0.39 & 0.42 & 0.47 & 0.58 \\
\hline PC2 & 0.23 & 0.62 & 0.42 & 0.15 & -0.16 & -0.63 \\
\hline \multicolumn{7}{|c|}{ (B) Gobiosoma bosc } \\
\hline \multirow[t]{2}{*}{ Axis } & $\mathrm{p}$ (var) & \multicolumn{5}{|c|}{ Loadings } \\
\hline & & $4 \mathrm{~m}$ & & $5 \mathrm{~mm}$ & $6 \mathrm{~mm}$ & $7 \mathrm{~mm}$ \\
\hline \multicolumn{7}{|c|}{ Cruise 1} \\
\hline PC1 & 0.66 & 0.3 & & 0.53 & 0.59 & 0.53 \\
\hline PC2 & 0.25 & 0.7 & & 0.33 & -0.15 & -0.57 \\
\hline \multicolumn{7}{|c|}{ Cruise 2} \\
\hline PC1 & 0.66 & 0.2 & & 0.46 & 0.58 & 0.63 \\
\hline PC2 & 0.21 & 0.7 & & 0.39 & -0.091 & -0.48 \\
\hline
\end{tabular}

among station-depth bins on each cruise (1-way analysis of variance: Cruise 1: $F_{5,180}=15, \mathrm{p}<0.0001$; Cruise 2: $F_{5,215}=29, \mathrm{p}<0.0001$ ). Salinity in the deeper 2 bins was significantly different from salinity in the shallower channel bins, and over the shoals (Tukey's Studentized range test).

Anchovy larvae were more concentrated at depth during the second cruise, but not during the first. During Cruise 1, small and large larvae were distributed similarly across station-depth bins (bin $\times$ size interaction, $\left.F_{5,340}=1.1, \mathrm{p}=0.38\right)$. The total concentration of larvae varied among bins $\left(F_{5,174}=3.7, \mathrm{p}=0.0032\right)$. There was a relatively low concentration of larvae at Stn E, with no effect of depth (Fig. 5A; Tukey's Studentized range test). During Cruise 2, small and large larvae were distributed differently across bins (bin $x$ size interaction: $F_{5,404}=2.5, \mathrm{p}=0.029$ ). Both size classes of larvae were most abundant in the deepest bins, and significantly less abundant in the shallow channel bins and over the $\mathrm{E}$ and $\mathrm{W}$ shoals (Fig. 5B; Tukey's Studentized range test). The increase in concentration with depth was more pronounced in the large larvae. Small larvae were $2.2 \times$ more concentrated at $8 \mathrm{~m}$ than at $2 \mathrm{~m}$, while large larvae were $3.7 \times$ more concentrated at $8 \mathrm{~m}$ than at $2 \mathrm{~m}$.

Vertical structuring of goby larvae was pronounced in both cruises. During both cruises, small and large gobies were distributed differently among stationdepth bins (bin $\times$ size interaction: Cruise $1, F_{5,348}=4.0$, 


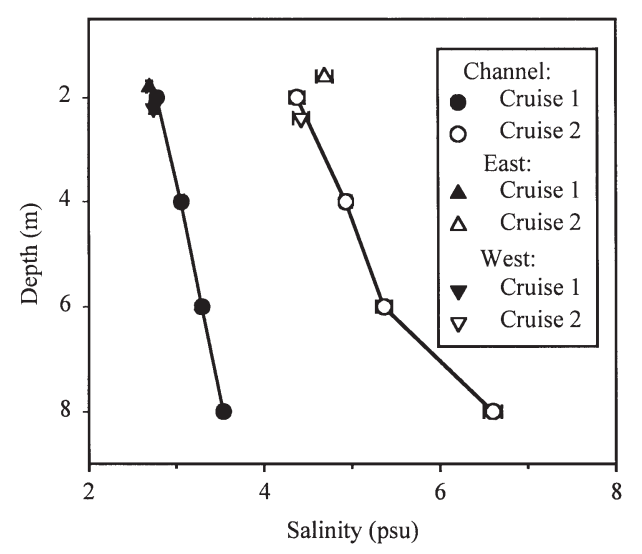

Fig. 4. Lateral and vertical structure of salinity along Main transect. Mean $( \pm \mathrm{SD})$ salinity is plotted for each stationdepth bin. For clarity, depth values for east and west shoal stations have been slightly offset from $2 \mathrm{~m}$
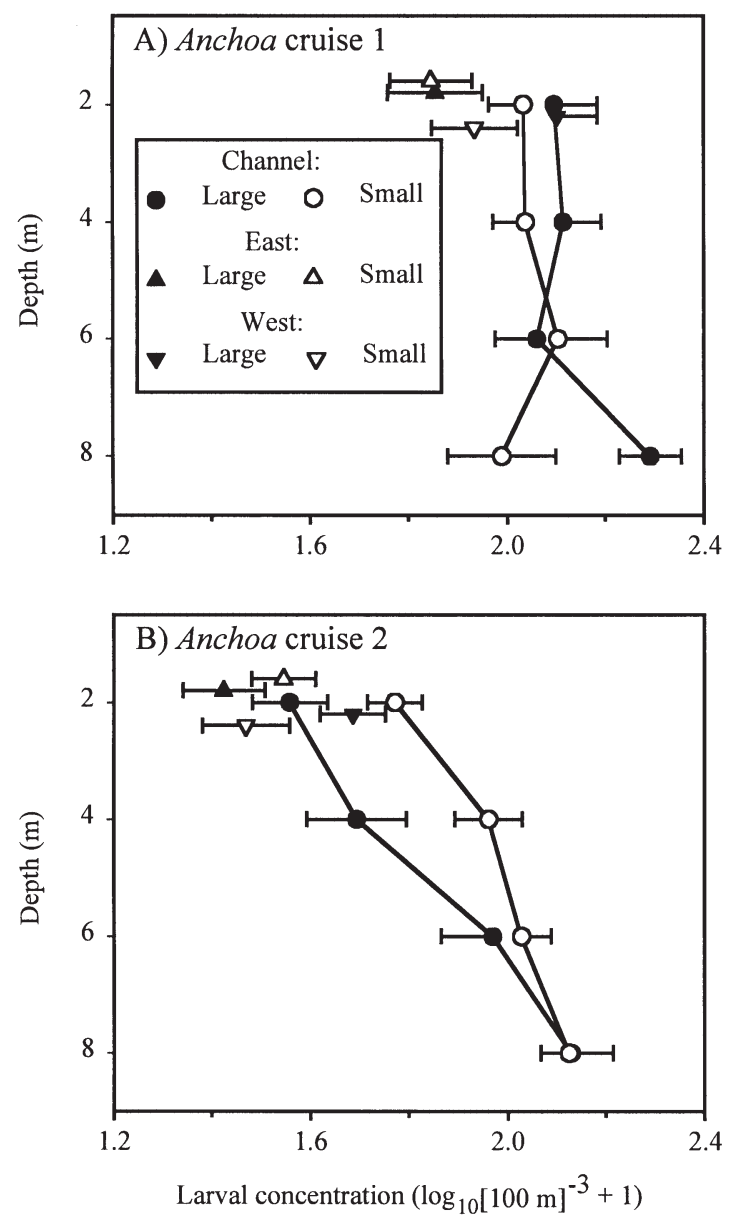

$\mathrm{p}=0.0015 ;$ Cruise 2, $\left.F_{5,406}=4.1, \mathrm{p}=0.0013\right)$. There were more goby larvae in deeper bins in the channel than in the shallower channel bins or over the shoals (Fig. 5C,D; Tukey's Studentized range test). The increase in concentration of larvae with increasing depth was more pronounced in large larvae. Small larvae were $2.6 \times$ and $3.1 \times$ more concentrated at 6 and $8 \mathrm{~m}$ than at the surface, in Cruises 1 and 2 respectively; large larvae were $6.3 \times$ and $9.2 \times$ more concentrated at greater depths.

\section{Harmonic analysis of current velocity, larval concentration and larval depth}

As expected, there was considerable periodic variability in mean along-channel current velocity at Main. In both cruises, the K1, M2 and M4 tidal constituents were significant, and explained $97 \%$ or more of the
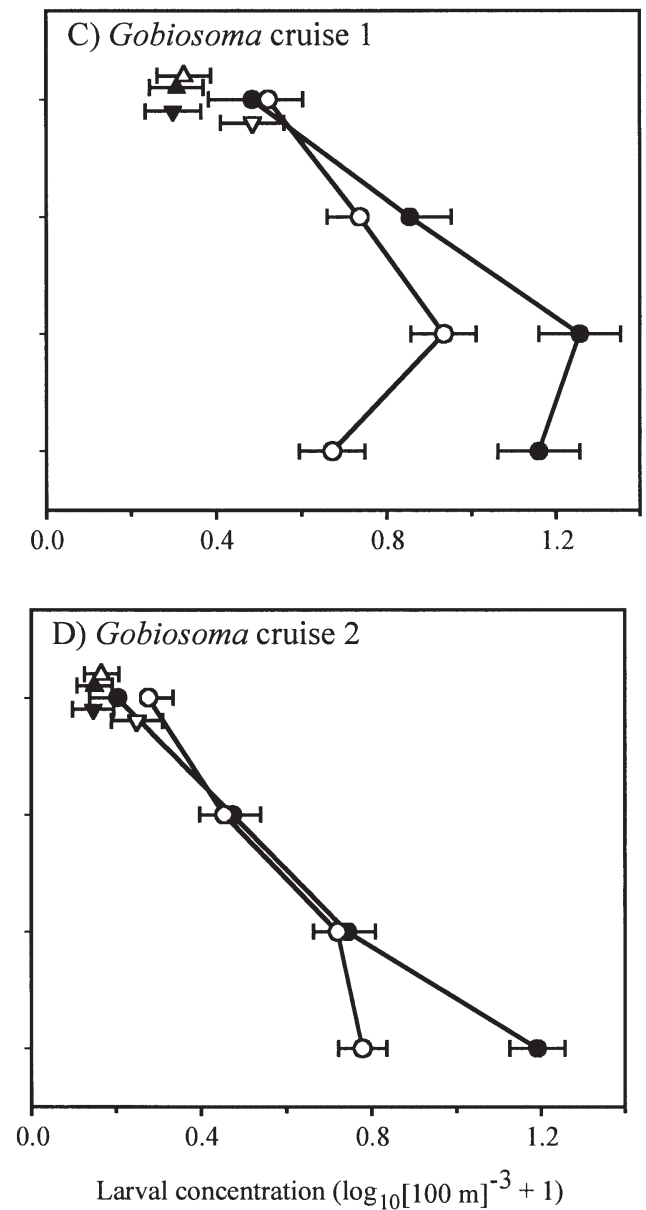

Fig. 5. Anchoa mitchilli and Gobiosoma bosc. Lateral and vertical structure of larval abundance (mean \pm SD) along Main transect. Larval concentration is plotted for each station-depth bin. For clarity, depth values for east and west shoal stations have been slightly offset from $2 \mathrm{~m}$, and only 1 side of the error bar is displayed for some points. (A), (B) Anchovy larvae during Cruises 1 and 2, respectively; (C), (D) goby larvae during Cruises 1 and 2, respectively. All cruise symbols as in key to (A) 
variance in observed values (Table 4). The M4 constituent during Cruise 2 was not significant after correcting for multiple testing. The amplitude of the M2 constituent exceeded that of the other 2 constituents (Table 4, Fig. 6). The overall amplitude of the tidal variability and the timing of maximum flood tide differed between Cruises 1 and 2. The amplitude was greater under spring tide conditions than under neap tide conditions. During the spring tide, maximum flood tides occurred around midday and midnight, whereas during neap tide maximum flood tides occurred around 03:00 and 15:00 h.

Anchovy larval abundance varied periodically, particularly on a K1 (day-night) periodicity during Cruise 2. Periodic components in depth-averaged larval concentration were greater during Cruise 2 than Cruise 1 (Table 5A, Fig. 7A). There was no periodic or day-to-day periodicity in the concentration of small anchovy larvae during Cruise 1. There was nominally significant K1 variability in the concentration of large anchovy larvae during Cruise 1, such that concentration was highest around midnight. This effect was not significant after correcting for multiple testing, however. During Cruise 2, the concentration of both small and large larvae varied with K1 periodicity. Peak concentrations of both large and small anchovy larvae occurred shortly after midnight (i.e. 02:00 to 04:00 h). Variability in the concentration of large larvae also included significant M2 and M4 constituents. Of the Cruise 2 effects, only the effect of K1 on large larvae was significant after correcting for multiple testing. The amount of variance explained by the harmonic regressions of larvae was less than the regressions of

Table 4. Temporal effects in harmonic regression of depthaveraged current. Regression statistics are reported separately for each cruise: coefficient of determination $\left(\mathrm{R}^{2}\right)$, firstorder and second-order predictors of day-to-day changes (Date, Date ${ }^{2}$ ), amplitude and phase-angle estimates for each tidal constituent (K1, M2, M4). Regression estimates are listed only if they are nominally $(\mathrm{p}<0.05)$ significant. A regression estimate is listed in bold if significant $(p<0.05)$ after correcting for multiple testing via sequential Bonferroni

\begin{tabular}{|lrr|}
\hline & Cruise 1 & Cruise 2 \\
\hline $\mathrm{R}^{2}$ & 0.99 & 0.97 \\
Date & 0 & 0 \\
Date & 0 & 0 \\
Amplitude & & \\
K1 & $\mathbf{9 . 8}$ & $\mathbf{7 . 5}$ \\
M2 & $\mathbf{6 1}$ & $\mathbf{4 5}$ \\
M4 & $\mathbf{6 . 9}$ & 6.1 \\
Phase angle & & \\
K1 & 146 & 120 \\
M2 & 40 & 27 \\
M4 & -59 & 250 \\
\hline
\end{tabular}

current velocity; only the model of large larvae during Cruise 2 explained $>50 \%$ of the observed variability. The regressions describe fluctuations in larval anchovy abundance over a factor of 3 (large larvae during

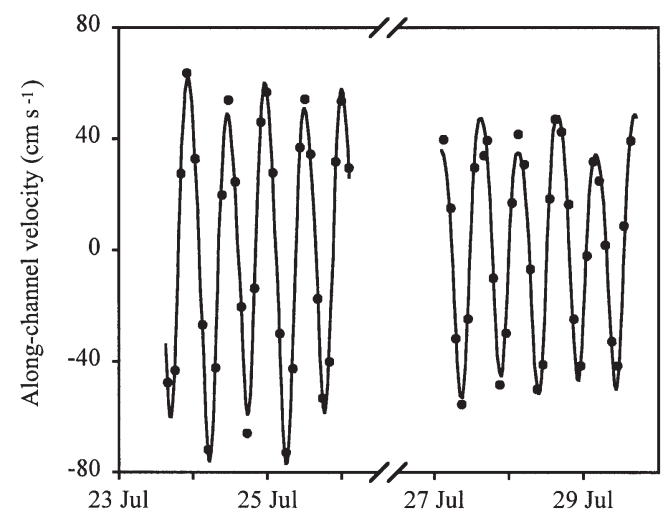

Fig. 6. Temporal variability in along-channel current velocity. Symbols represent observed depth-averaged velocity, and lines the fitted relationships based on harmonic regression, including only those predictors that were nominally $(\mathrm{p}<0.05)$ significant

Table 5. Anchoa mitchilli and Gobiosoma bosc. Temporal effects in harmonic regression of depth-averaged larval concentration. Regression statistics are reported separately for each cruise and size class of larvae. Further details as in Table 4

\begin{tabular}{|c|c|c|c|c|}
\hline & \multicolumn{2}{|c|}{ Cruise 1} & \multicolumn{2}{|c|}{ Cruise 2} \\
\hline & Small & Large & Small & Large \\
\hline \multicolumn{5}{|c|}{ (A) Anchoa mitchilli } \\
\hline $\mathrm{R}^{2}$ & 0 & 0.42 & 0.27 & 0.75 \\
\hline Date & 0 & 0 & 0 & -0.0072 \\
\hline Date $^{2}$ & 0 & -0.00041 & 0 & 0 \\
\hline \multicolumn{5}{|c|}{ Amplitude } \\
\hline K1 & 0 & 0.21 & 0.19 & 0.33 \\
\hline M2 & 0 & 0 & 0 & 0.17 \\
\hline M4 & 0 & 0 & 0 & 0.18 \\
\hline \multicolumn{5}{|c|}{ Phase angle } \\
\hline K1 & & -150 & -110 & -120 \\
\hline M2 & & & & -14 \\
\hline M4 & & & & 63 \\
\hline \multicolumn{5}{|c|}{ (B) Gobiosoma bosc } \\
\hline $\mathrm{R}^{2}$ & 0.26 & 0 & 0.39 & 0.48 \\
\hline Date & 0 & 0 & 0 & 0 \\
\hline Date $^{2}$ & 0 & 0 & 0 & 0 \\
\hline \multicolumn{5}{|c|}{ Amplitude } \\
\hline $\mathrm{K} 1$ & 0 & 0 & 0.24 & 0.34 \\
\hline M2 & 0.28 & 0 & 0 & 0 \\
\hline M4 & 0 & 0 & 0 & 0 \\
\hline \multicolumn{5}{|c|}{ Phase angle } \\
\hline $\mathrm{K} 1$ & & & -130 & -150 \\
\hline M2 & -160 & & & \\
\hline M4 & & & & \\
\hline
\end{tabular}




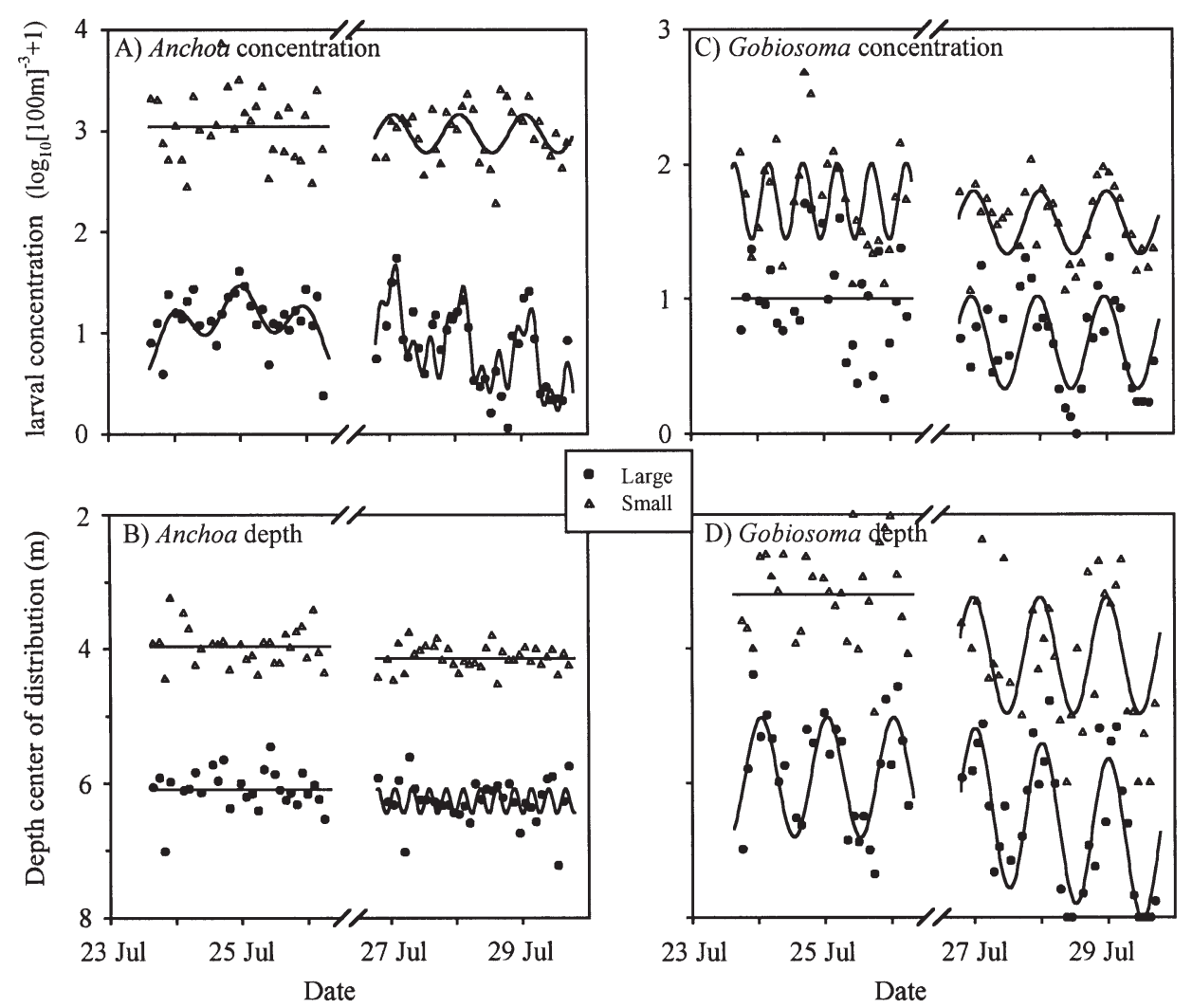

Fig. 7. Anchoa mitchilli and Gobiosoma bosc. Temporal variability in larval abundance and depth distribution. Symbols represent observed values, and lines the fitted relationship based on harmonic regression, including only those predictors that were nominally ( $\mathrm{p}$ <.05) significant. (A) Anchovy larval abundance, for clarity, values for small larvae have been shifted up 1 increment on the $y$-axis, and values for large larvae have been shifted down 1 increment. (B) Anchovy larvae mean depth, values for small larvae have been shifted up (shallower) 1 increment on the $y$-axis, and values for large larvae have been shifted down (deeper) 1 increment. (C) Goby larval concentration, values for small larvae have been shifted up 1 increment. (D) Goby larvae mean depth, values for small larvae have been shifted up (shallower) 2 increments on the $y$-axis. Key applies to all graphs

Cruise 1, small larvae during Cruise 2) to 1 order of magnitude (large larvae during Cruise 2).

There was no pronounced periodic variability in the mean depth of anchovy larvae (Fig. 7B). Only among the large larvae during Cruise 2 was any temporal predictor (M4) nominally significant, and this predictor was not significant after correcting for multiple testing. The mean depth of both small and large anchovy larvae was roughly $5 \mathrm{~m}$.

Goby larval abundance varied periodically, especially over the day-night periodicity during Cruise 2 . During Cruise 1, there was a nominally significant M2 periodicity in the abundance of small goby larvae, but this effect was not significant after correcting for multiple testing (Table 5B, Fig. 7C). During Cruise 2, the concentration of both small and large goby larvae varied with a K1 periodicity; only the effect on large larvae was significant after correcting for multiple testing. Peak concentrations occurred around midnight. The periodic variability resolved by the regressions describes fluctuations in larval abundance up to a factor of 4 (large larvae during Cruise 2).
The mean depth of goby larvae usually varied on a day/night cycle. Among large gobies during Cruise 1, and both sizes during Cruise 2, the K1 effect was significant (Table 6). The effect was significant after correcting for multiple testing among large goby larvae from both cruises, but not for small goby larvae during Cruise 2. Among these groups, the predicted mean depth varied over the day from about 7 to about $5 \mathrm{~m}$ (Fig. 7D). In all groups, predicted mean depth was shallowest at midnight.

Larval concentration and depth distribution were related to along-channel current speed in 1 case only. Among the small goby larvae in Cruise 1, there was a significant relationship (bivariate regression, slope = -0.0047 , Student's $t=-3.0, \mathrm{p}=0.0069$ ). The negative slope indicates that the sampled abundance of the small goby larvae was highest when the downriver flow of the current was greatest. The nominal significance of this result is just short of the Bonferroni criterion for analysis-wide significance ( $p=0.05 / 8$ tests $=0.0625$ ). No other dataset of larval concentration or mean depth was significantly related to the along-channel velocity. 
Table 6. Gobiosoma bosc. Temporal effects in harmonic regression of mean depth of larvae. Regression statistics are reported separately for each cruise and size class of larvae. Further details as in Table 4

\begin{tabular}{|lrrrr|} 
& \multicolumn{2}{c}{ Cruise 1 } & \multicolumn{2}{c|}{ Cruise 2 } \\
& Small & Large & Small & Large \\
\hline $\mathrm{R}^{2}$ & 0 & 0.58 & 0.33 & 0.74 \\
Date & 0 & 0 & 0 & 0.0094 \\
Date & & 0 & 0 & 0 \\
Amplitude & 0 & & & \\
K1 & 0 & $\mathbf{0 . 8 9}$ & 0.87 & $\mathbf{1 . 1}$ \\
M2 & 0 & 0 & 0 & 0 \\
M4 & 0 & 0 & 0 & 0 \\
Phase angle & & & & \\
K1 & & 48 & 36 & 47 \\
M2 & & & & \\
M4 & & & & \\
\end{tabular}

\section{DISCUSSION}

Anchovy and goby larvae exhibited a depth distribution that is consistent with upriver transport. Anchovy larvae of both size groups were more concentrated at depth (Fig. 5), particularly during neap tide conditions during Cruise 2. We also found the highest concentration in deeper bins during Cruise 1, but the change with depth was less pronounced than during the second cruise and was not significant. We collected higher concentrations of both small and large goby larvae at depth in both cruises. The increase with increasing depth was more pronounced in large goby larvae than in small goby larvae, and more pronounced during Cruise 2 than Cruise 1. A preference for deeper water will promote along-river movement in systems where residual flow has an upstream velocity component. In partially mixed estuaries such as the Hudson River, residual flow depends on depth in the water column (Pritchard 1956, Hansen \& Rattray 1966, Officer 1976), bathymetry (Wong 1994, Valle-Levinson \& Lwiza 1995), and Ekman number $\left(k_{z} / f H^{2}\right.$, where $k_{z}$ is the eddy viscosity, $f$ is the Coriolis parameter, and $H$ is the water depth [Kasai et al. 2000]). In deeper portions of the water column of the Hudson River estuary, residual flow is in fact upstream (Abood 1977, E.T.S. \& K.M.M.L. unpubl. data). A preference for depth may be the sole mechanism promoting up-estuary transport in some species (Melville-Smith et al. 1981).

Lateral effects on larval concentration were consistent but relatively minor. During both cruises, there were fewer larvae of both species over the east shoal than over the west shoal or in the channel (Fig. 5). Given the relatively small magnitude of this difference, it appears that anchovy larval abundance can be accurately estimated by sampling in the channel.
Harmonic regression analysis detected significant periodic temporal variability in larval concentration and depth distribution. The dominant periodic effect was a day/night difference. Larvae were more concentrated in the sampled portion of the water column at night (Fig. 7A,C). While we found nominally significant day/night effects in 5 of the 8 species/size/cruise combinations, and other constituents (M2, M4) were nominally significant in at least 1 of the combinations, only the day-night effects on large larvae of both species during Cruise 2 were significant, once nominal significance was corrected for multiple testing. The day/night amplitude in abundance was 4 - to 10-fold in large anchovy and goby larvae. We also found periodic variability in depth distribution among goby larvae (Fig. 7D). The mean depth of large goby larvae in both cruises, and small larvae during the second cruise, was shallowest at night (the latter was not significant after multiple-testing correction). The predicted changes in depth from the regression were $2 \mathrm{~m}$ or more.

The periodic changes are consistent with diel vertical migration. Interpretation of the pattern shown by large goby larvae during Cruise 2 is most straightforward: larvae were most concentrated, and shallowest, during the night. During the day, larvae moved deeper and some portion of these larvae moved below the depth range sampled by our gear. A slightly different pattern was shown by large goby larvae during Cruise 1, wherein there was periodic change in mean depth without periodic change in concentration. This scenario suggests that relatively few large larvae were moving into the sampled depth range at night and back down during the day. Yet a third pattern was shown by large anchovy larvae: their concentration changed without concomitant changes in mean depth. Here larval concentrations varied synchronously, and to the same degree at all depths sampled. This was corroborated by other analyses, which demonstrated no among-depth differences in harmonic regression predictors (results not shown). This is consistent with vertical migration if all larvae, including those from the deep unsampled bins, were moving up in sufficient numbers to cause concentrations to peak at the same time in all sampled depth bins. To confirm this scenario, sampling over the entire water column would be necessary using an epibenthic trawl in addition to the midwater trawl.

Day/night differences in net avoidance will also generate higher catch rates at night. Any diel variability in avoidance, because of visual reactivity or diel changes in responsiveness, will confound efforts to characterize diel changes in water column abundance and vertical distribution (Olney 1996). The fact that periodic day/ night fluctuations in catch were not always detected (i.e. were absent among small anchovy during Cruise 1, 
and both sizes of goby during Cruise 2) suggests that the diel avoidance component was relatively minor. Note that day/night differences in avoidance may be a small component of overall avoidance patterns, because larvae may react to pressure waves associated with the net and its bridle even at night (Smith \& Richardson 1977). We have concluded that larval avoidance of our gear in the Hudson River is likely to have been substantially less than reported elsewhere, probably because of higher turbidity.

Following the approach of Leak \& Houde (1987), we applied the avoidance estimates derived by Murphy \& Clutter for a tropical anchovy. Using this correction, the overall abundance of large anchovy larvae in our samples was predicted to be nearly 2 orders of magnitude greater than the abundance of small larvae, an unrealistic outcome considering that our samples were taken during the spawning season and anchovy larval mortality rates are estimated to be $25 \% \mathrm{~d}^{-1}$ (Houde \& Zastrow 1991). We therefore interpret our variations in catch rate as reflective of actual concentrations, but our conclusions are tempered by the lack of relevant direct estimates of avoidance and its day/night variability.

Diel vertical movement in older larval fishes can be associated with gas bladder inflation. It is logical that inflation of a gas bladder would facilitate vertical migration. Larvae of herring and anchovy (Hoss et al. 1989, Forward et al. 1994, Uotani et al. 2000), and more evolutionarily derived bony fish species (Kitajima et al. 1998, Shoji et al. 1999) inflate their gas bladder by gulping air at the surface at night, deflating the bladder during the day. Possible functions of this behavior include nocturnal energy conservation, more efficient predator evasion, and the facilitation of transport (Hoss et al. 1989). Careful examination of Anchoa mitchilli larvae in the Chesapeake Bay revealed that inflated gas bladders were more prevalent among larger larvae (>11 mm), but were nonetheless observed in half of 6 to $7 \mathrm{~mm}$ larvae that were captured at night, and in larvae as small as 4 to $5 \mathrm{~mm}$ (North 2001). Thus, virtually all the larvae in our small class would be capable of gas bladder inflation, and these larvae did exhibit diel migration. Among large larvae, diel migration was more pronounced, and North's (2001) results indicate that bladder inflation is more prevalent at this size. The development of day-night movement in the northern anchovy Engraulis mordax appears to coincide with gas bladder inflation (Hunter \& Sanchez 1976). It is noteworthy that movement to the surface for gas bladder inflation is not tightly synchronized. Synchronous movement at dusk would concentrate larvae at the surface, which we did not observe. Gas bladder inflation may facilitate vertical migration in gobies as well. Prominent gas bladders are seen in the smallest goby larval stages (Lippson \& Moran 1974, authors' pers. obs.). The paucity of goby larvae in the shallowest bins would suggest that surface inflation is not required in this species.

How well do our findings conform to those expected if vertical migration functions (in part) to facilitate along-river movement? The temporal changes in larval distribution and abundance we observed were not consistent with strictly tidally entrained migration (selective tidal stream transport). Larval abundance did not peak during each flood tide, nor were larvae shallowest during each flood tide. There was no relationship between larval concentration and along-river current velocity, except in the case of small goby larvae during Cruise 1. In this case, larvae were most abundant during each ebbing tide, which would promote downriver movement. Although vertical movement was not tidally synchronized, nocturnal upward migration was roughly coincident with flood tide during both Cruise 1 and Cruise 2. Similar combined flood/ebb M2 tide and day/night effects on vertical distribution have been seen in a variety of estuarine fish larvae (e.g. Weinstein et al. 1980, Forward et al. 1999, Grioche et al. 2000), while in other species movements were solely synchronized to the M2 tide (e.g. Fortier \& Leggett 1983, Rowe \& Epifanio 1994, Jager 1999) or to the day/night cycle (Fortier \& Leggett 1983). Diel migration of the kind we have observed, with movement into the water column during night flood tides and down towards the bottom at other times, can promote upriver transport (Hill 1991).

Whether the vertical migration pattern suggested by our results is likely to promote substantive along-river transport, and the relative importance of vertical migration versus simple depth preferences, need to be quantified. The next step to be taken with our data is to project larval advection rates (Rowe \& Epifanio 1994, Jager \& Mulder 1999) by combining vertical preferences and vertical migration scenarios with information on local flow retrieved from the ADCP. Such analyses were outside the scope of this study.

An intriguing feature of the temporal effects on larval concentration is the contrast between spring tide and neap tide results. The amplitude of periodic changes in concentration and mean depth, and the degree to which there is a preference for greater depths, tended to be smaller during spring tide than neap tide. We suggest that this difference reflects more turbulent mixing during spring tide, with reduced stratification of the water column and more uniform distribution of larvae. However, our spring-neap comparison was not replicated, and satisfactory tests of this possibility will require a more dedicated study design. The generality of this result can be further tested because it generates a strong prediction: upriver transport should be more pronounced during neap tide periods than during 
spring tide periods. Frequent surveys of along-river distribution or analyses of individual transport history via otolith microchemistry (e.g. Kimura et al. 2000), would be able to test this prediction.

Comparison of our results and previous reports suggests that vertical distribution patterns of Anchoa mitchilli larvae may vary according to local conditions. A $40 \mathrm{~h}$ series of samples in Narragansett Bay suggested that larvae moved upwards at night and downwards during the day (Bourne \& Govoni 1988). In contrast, Loos \& Perry (1991) found that small larvae $(<12 \mathrm{~mm})$ remained in deeper water in the Patuxent River and did not show any temporal change in vertical distribution, while larger larvae were shallower during the day and deeper at night. Neither study attempted to relate vertical distribution of larvae to tidal constituents. Sampling on a coarser temporal scale (ca. every $6 \mathrm{~h}$ ), Olney (1996) found that postflexion anchovy larvae at the mouth of Chesapeake Bay were shallowest at midnight, coinciding with a flood tide. Analysis of our previous (1995 and 1996) Hudson River sampling efforts, which took comparatively few samples at lower frequency, revealed no consistent pattern of depth distribution or periodic changes in depth (Schultz et al. 2000). In contrast to conditions during the previous years of sampling, during 1998 larvae were fairly uniformly distributed along the sampled portion of the river (Fig. 3). This is notable because temporal variability in larval concentration at a site can be dominated by tidal movement of along-river gradients (Schultz et al. 2000). Conversely, temporal variability in the absence of strong along-river gradients, as in the present study, will better reflect any vertical movements of larvae.

The ultimate goal of our study of larval transport is to predict along-river movement from local patterns of larval distribution. Previous studies have indicated upestuary movement of Anchoa mitchilli larvae. A seasonal up-bay shift in larval and juvenile $A$. mitchilli was found in Chesapeake Bay (Wang \& Houde 1995) and the Hudson River (Dovel 1981, Schmidt 1992). Clear evidence for larval migration was found in the Patuxent River (Loos \& Perry 1991). Whereas the smallest larvae ( 2 and $3 \mathrm{~mm}$ ) were most concentrated in the lower portions of the river, larger larvae (11 $\mathrm{mm}$ and up) were more concentrated in upriver sections than in lower sections. Further evidence for movement of larvae into upriver sections was that the wholeseason standing stock of the larger larvae (17 to $23 \mathrm{~mm}$ ) exceeded the standing stock of medium-sized larvae (8 to $14 \mathrm{~mm}$ ) in the river. Most recently, an analysis of movement at the individual level in Chesapeake Bay has been completed using otolith microchemistry as a record of salinity history (Kimura et al. 2000). Movement into lowersalinity water was confirmed, but only in individuals larger than $25 \mathrm{~mm}$, i.e. considerably larger than the larvae we collected in the Hudson River estuary. The larger fish may accomplish along-estuary movement via directed horizontal swimming and not by depth preference or vertical migration.

There are also previous reports of up-estuary movement of Gobiosoma bosc larvae. Small larvae have been collected in the York River unexpectedly far upriver from G. bosc spawning grounds (Massman et al. 1963). A pattern of upriver increase in larval length in the Patuxent River yielded a migration rate estimate of $1 \mathrm{~km} \mathrm{~d}^{-1}$ (Shenker et al. 1983).

We suggest that harmonic regression techniques merit wider application in studies of estuarine transport mechanisms (see also Bell et al. 2001). Thorough quantitative analyses of periodic changes in abundance have typically relied on linear modeling, such as analyses of variance (e.g. Weinstein et al. 1980, Rowe \& Epifanio 1994, Forward et al. 1999, Jager 1999) or time-series models (e.g. Fortier \& Leggett 1982). Analysis-of-variance models (or their nonparametric equivalents) require that time be coded as categories (day/night, flood/ebb, etc.). Treating time as a category causes loss of information. Spectral time-series analysis is more appropriate because time is treated as a continuous variable. Methods of time-series analysis, like the analysis of variance approach, decompose variance in a quantitative variable into portions that are explained by different temporal periods, and residual error. Many approaches are available within the time-series methods (Bloomfield 1976, Legendre \& Dutelleul 1992, Emery \& Thomson 1997). Of these, harmonic analysis is especially suitable for data in which observations are not taken at precise intervals, unlike other familiar approaches such as spectral analysis or periodograms. Another advantage is that fewer observations are needed than required by some time-series methods, particularly spectral analysis. Two limitations trade off against this flexibility. One is that the harmonic regression approach assumes that variation at each periodicity can be fitted to a sinusoidal curve (although the summed periodicities of several components may not be sinusoidal). While tidal flow data conform well to sinusoidal modeling, periodic changes in larval abundance or depth could take another form, and would not be well fit to harmonic regression models. Another limitation is that harmonic regression requires a priori specification of the testing interval. This requirement was easily met in our case, because we wished to test specific hypotheses about the periodicity of larval distribution and abundance.

Acknowledgements. We thank Bill Wise of the Living Marine Research Institute, State University of New York, and Captain $\mathrm{S}$. Cluett and the crew of RV 'Onrust', for cruise planning and 
execution. We are grateful to Tom Wilson and the staff of the Ocean Instrument Laboratory, State University of New York, for sampling instrumentation used in this study. Assistance with the cruises and/or with the larval samples was provided by J. Arora, R. Barboza, M. Berube, B. Doerr, C. Chizinski, C. Delavalle, D. Ely, K. Freidenburg, G. Goad, A. Gospodarek, N. Henderson, C. Obergfell, T. Hurst, P. Kelly, A. Legassey, V. Mendillo, C. Miller, A. Norton, G. Siena, J. Waite and S. Zahner. Several individuals provided special technical assistance, including E. Lorda, W. K. Macy III, C. Obergfell, and J. Young. The Gobiosoma bosc results comprised part of M.C.F.'s honors thesis, written under the auspices of the UConn Honors Program. Several anonymous reviewers provided many constructive suggestions on the manuscript. The research presented in this paper was funded by the Hudson River Foundation. This paper is dedicated to the victims of 11 September 2001 and their families.

\section{Appendix 1. Mean depth}

The mean depth of larvae, also known as the depth center of distribution $(Z C D)$, was estimated as

$$
Z C D=\Sigma\left(P_{i} \times Z_{i}\right)
$$

where

$$
P_{i}=\left(C_{i} \times H_{i}\right) / \Sigma\left(C_{i} \times H_{i}\right)
$$

$i=1$ to $n, n$ is the number of depth strata, $C_{i}$ is the (log-transformed) concentration of larvae in the $i$ th depth stratum, $H_{i}$ is the width of the $i$ th depth stratum (always $2 \mathrm{~m}$ in this case), and $Z_{i}$ is the mean depth of the $i$ th depth stratum $(2,4,6$ or $8 \mathrm{~m})$

\section{Appendix 2. Regression model construction}

K1, M2 and M4 tidal constituents were each included as $A \cos (\omega t+\phi)$, where $A$ is the amplitude of the periodic variability, $\omega$ is the angular frequency of the variability $(2 \pi / T$, where $T$ is the period of the constituent in $h)$, and $\phi$ is the phase-shift of the variability with respect to a selected reference time, $t_{0}$. The $t_{0}$ used for the phase-shift estimates is conventionally $00: 00 \mathrm{~h}$ on January 1 of the year. Periodic tidal constituents $A \cos (\omega t+\phi)$ can be linearized for inclusion in multiple regression as follows. Because

$$
\cos (\theta+\gamma)=\cos (\theta) \cos (\gamma)-\sin (\theta) \sin (\gamma)
$$

each tidal component can be represented in a multiple regression as 2 terms,

where

$$
\alpha \cos (\omega t)+\beta \sin (\omega t)
$$

$$
\alpha=\mathrm{A} \cos (\phi), \beta=-\mathrm{A} \sin (\phi)
$$

The amplitude $A$ is then given by $\left(\alpha^{2}+\beta^{2}\right)^{-}$, and $\phi$ is arc$\tan (\beta / \alpha)$. The standard error for $\mathrm{A}$ is $\left(\mathrm{SE}_{\alpha}{ }^{2}+\mathrm{SE}_{\beta}{ }^{2}\right)-$, where $\mathrm{SE}_{\alpha}$ and $\mathrm{SE}_{\beta}$ are the standard errors for the regression estimates (contra Bliss 1958). The significance of a tidal constituent is assessed by Student's $t$-test against the null hypothesis that the value is 0 (1-tailed, because amplitude values are always positive)

\section{LITERATURE CITED}

Abood KA (1977) Evaluation of circulation in partially stratified estuaries as typified by the Hudson River. PhD thesis, Rutgers University, New Brunswick, NJ

Baird D, Ulanowicz RE (1989) The seasonal dynamics of the Chesapeake Bay ecosystem. Ecol Monogr 59:329-364

Batschelet E (1979) Introduction to mathematics for life scientists. Springer-Verlag, Berlin

Bell KN, Cowley PD, Whitfield AK (2001) Seasonality in frequency of marine access to an intermittently open estuary: implications for recruitment strategies. Estuar Coast Shelf Sci 52:327-337

Bliss CI (1958) Periodic regression in biology and climatology. Bull no 615. Connecticut Agricultural Experiment Station, New Haven

Bloomfield P (1976) Fourier analysis of time series: an introduction. John Wiley \& Sons, New York

Boehlert GW, Mundy BC (1988) Roles of behavioral and physical factors in larval and juvenile fish recruitment to estuarine nursery areas. In: Weinstein MP (ed) Larval fish and shellfish transport through inlets. American Fisheries Society Symposium, Vol 3. American Fisheries Society, Bethesda, MD, p 51-67

Bourne DW, Govoni JJ (1988) Distribution of fish eggs and larvae and patterns of water circulation in Narragansett Bay, 1972-1973. In: Weinstein MP (ed) Larval fish and shellfish transport through inlets, Vol 3. American Fisheries Society, Bethesda, MD, p 132-148

Day JW Jr, Hall CAS, Kemp WM, Yanez-Arancibia A (1989) Estuarine ecology. John Wiley \& Sons, New York

Dovel WL (1971) Fish eggs and larvae of the upper Chesapeake Bay. Natural Resources Institute Special Report 4. University of Maryland, College Park

Dovel WL (1981) Ichthyoplankton of the Lower Hudson estuary, New York. NY Fish Game J 28:21-39

Emery WJ, Thomson RE (1997) Data analysis methods in physical oceanography. Pergamon Press, Tarrytown, NY

Fortier L, Leggett WC (1982) Fickian transport and the dispersal of fish larvae in estuaries. Can J Fish Aquat Sci 39: 1150-1163

Fortier L, Leggett WC (1983) Vertical migrations and transport of larval fish in a partially mixed estuary. Can J Fish Aquat Sci 40:1543-1555

Forward RB Jr, Hettler WF, Hoss DE (1994) Swimbladder deflation in the Atlantic menhaden, Brevoortia tyrannus. Fish Bull US Dept Commerce 92:641-646

Forward RB, Jr, Reinsel KA, Peters DS, Tankersley RA and 5 others (1999) Transport of fish larvae through a tidal inlet. Fish Oceanogr 8:153-172

Geyer WR (1995) Tide-induced mixing in the Amazon frontal zone. J Geophys Res C Oceans 100:2341-2353

Grioche A, Harlay X, Koubbi P, Lago LF (2000) Vertical migrations of fish larvae: Eulerian and Lagrangian observations in the eastern English Channel. J Plankton Res 22: 1813-1828

Hansen D, Rattray M Jr (1966) New dimensions in estuary classification. Limnol Oceanogr 11:319-326

Hill AE (1991) A mechanism for horizontal zooplankton transport by vertical migration in tidal currents. Mar Biol 111: 485-492

Holt SA, Holt GJ, Arnold CR (1989) Tidal stream transport of larval fishes into non-stratified estuaries. Rapp. P-V Réun Cons Int Explor Mer 191:100-104

Hoss DE, Checkley DM Jr, Settle LR (1989) Diurnal buoyancy changes in larval Atlantic menhaden (Brevoortia tyrannus). Rapp P-V Réun Cons Int Explor Mer 191:105-111 
Houde ED, Zastrow CE (1991) Bay anchovy. In: Funderbuck SL, Jordan SJ, Mihursky JA, Riley D (eds) Habitat requirements for Chesapeake Bay living resources. Living Resources Subcommittee, Chesapeake Bay Program, Solomons, MD, p 81-811

Hunter JR, Sanchez C (1976) Diel changes in swim bladder inflation of the larvae of the northern anchovy, Engraulis mordax. Fish Bull US Dept Commerce 74:847-855

Jager Z (1999) Selective tidal stream transport of flounder larvae (Platichthys flesus L.) in the Dollard (Ems Estuary). Estuar Coast Shelf Sci 49:347-362

Jager Z, Mulder HPJ (1999) Transport velocity of flounder larvae (Platichthys flesus L.) in the Dollard (Ems Estuary). Estuar Coast Shelf Sci 49:327-346

Kasai A, Hill A, Fujiwara T, Simpson J (2000) Effects of the earth's rotation on the circulation in regions of freshwater influence. J Geophys Res C Oceans 105:16961-16969

Kimura R, Secor DH, Houde ED, Piccoli PM (2000) Up-estuary dispersal of young-of-the-year bay anchovy Anchoa mitchilli in the Chesapeake Bay: inferences from microprobe analysis of strontium in otoliths. Mar Ecol Prog Ser 208: 217-227

Kitajima C, Yamane Y, Matsui S, Yoshimatsu T (1998) Ontogenetic change in specific gravity in the early stages of the ayu Plecoglossus altivelis. Bull Jpn Soc Sci Fish 64:822-829

Laprise R, Dodson JJ (1989) Ontogeny and importance of tidal vertical migrations in the retention of larval smelt Osmerus mordax in a well-mixed estuary. Mar Ecol Prog Ser 55:101-111

Leak JC, Houde ED (1987) Cohort growth and survival of bay anchovy Anchoa mitchilli larvae in Biscayne Bay, Florida. Mar Ecol Prog Ser 37:109-122

Legendre P, Dutelleul P (1992) Introduction to the analysis of periodic phenomena. In: Ali MA (ed) Rhythms in fishes. Plenum Press, New York, p 11-25

Lippson AJ, Moran RL (1974) Manual for identification of early developmental stages of fishes of the Potomac River Estuary, Maryland Department of Natural Resources, Baltimore, MD

Loos JJ, Perry ES (1991) Larval migration and mortality rates of bay anchovy in the Patuxent River. In: Hoyt RD (ed) Larval fish recruitment and research in the Americas, National Oceanic Atmospheric Administration Technical Report NMFS 95, Washington, DC, p 65-76

Massman WH, Norcross JJ, Joseph EB (1963) Distribution of larvae of the naked goby, Gobiosoma bosci, in the York River. Chesapeake Sci 4:120-125

McHugh JL (1967) Estuarine nekton. In: Lauff GH (ed) Estuaries. American Association for the Advancement of Science, Washington, DC, p 581-620

McLellan HJ (1965) Elements of physical oceanography. Pergamon Press, Oxford

Melville-Smith R, Baird D, Wooldridge T (1981) The utilization of tidal currents by the larvae of an estuarine fish. S Afr J Zool 16:10-13

Murphy GI, Clutter RI (1972) Sampling anchovy larvae with a plankton purse seine. Fish Bull US Dept Commerce 70: 789-798

Norcross BL, Shaw RF (1984) Oceanic and estuarine transport of fish eggs and larvae: a review. Trans Am Fish Soc 115: 155-165

North EW (2001) Transport and retention of fish early-life stages in Chesapeake Bay: mechanisms and implications for recruitment. PhD thesis, University of Maryland, College Park

Officer C (1976) Physical oceanography of estuaries (and associated coastal waters). John Wiley, Chichester
Olney JE (1996) Community structure, small scale patchiness, transport, and feeding of larval fishes in an estuarine plume. PhD thesis, University of Maryland, College Park

Peters H (1997) Observations of stratified turbulent mixing in an estuary: neap-to-spring variations during high river flow. Estuar Coast Shelf Sci 45:69-88

Pritchard DW (1956) The dynamic structure of a coastal plain estuary. J Mar Res 15:33-42

Pugh DT (1987) Tides, surges and mean sea-level. John Wiley \& Sons, New York

Rice WR (1989) Analyzing tables of statistical tests. Evolution 43:223-225

Rowe PM, Epifanio CE (1994) Tidal stream transport of weakfish larvae in Delaware Bay, USA. Mar Ecol Prog Ser 110: 105-114

Schmidt RE (1992) Temporal and spatial distribution of bay anchovy eggs through adults in the Hudson River. In: Smith CL (ed) Estuarine research in the 1980's. State University of New York Press, Albany, NY, p 228-241

Schultz ET, Cowen RK, Lwiza KMM, Gospodarek AM (2000) Explaining advection: do larval bay anchovy (Anchoa mitchilli) show selective tidal stream transport? ICES J Mar Sci 57:360-371

Shenker JM, Hepner DJ, Frere PE, Currence LE, Wakefield WW (1983) Upriver migration and abundance of naked goby (Gobiosoma bosci) larvae in the Patuxent River estuary, Maryland. Estuaries 6:36-42

Shoji J, Maehara T, Tanaka M (1999) Diel vertical movement and feeding rhythm of Japanese Spanish mackerel larvae in the central Seto Inland Sea. Fish Sci 65:726-730

Smith PE, Richardson SL (1977) Standard techniques for pelagic fish egg and larva surveys. Food and Agriculture Organization of the United Nations, Rome

Uotani I, Fukui A, Osaki K, Ozawa T (2000) Experimental study on the inflation and deflation of gas bladder of Japanese anchovy, Engraulis japonicus larvae. Bull Mar Sci 66:97-103

Valle-Levinson A, Lwiza KMM (1995) The effects of channels and shoals on exchange between the Chesapeake Bay and the adjacent ocean. J Geophys Res C Oceans 100: 18551-18563

Vouglitois JJ, Able KW, Kurtz RJ, Tighe KA (1987) Life history and population dynamics of the bay anchovy in New Jersey. Trans Am Fish Soc 116:141-153

Wang SB, Houde ED (1995) Distribution, relative abundance, biomass and production of bay anchovy Anchoa mitchilli in the Chesapeake Bay. Mar Ecol Prog Ser 121:27-38

Wang JC, Kernehan RJ (1979) Fishes of the Delaware estuaries: a guide to the early life history. EA Communications, Towson, MD

Webb KL, D'Elia CF (1980) Nutrient and oxygen redistribution during a spring neap tidal cycle. Science 207: 983-985

Weinstein MP, Weiss SL, Hodson RG, Gerry LR (1980) Retention of three taxa of postlarval fishes in an intensively flushed tidal estuary, Cape Fear River, North Carolina. Fish Bull US Dept Commerce 78:419-436

Welch JM, Forward RB Jr, Howd PA (1999) Behavioral responses of blue crab Callinectes sapidus postlarvae to turbulence: implications for selective tidal stream transport. Mar Ecol Prog Ser 179:135-143

Wong KC (1994) On the nature of transverse variability in a coastal plain estuary. J Geophys Res C Oceans 99: 14209-14222

Yamashita Y, Tsuruta Y, Yamada H (1996) Transport and settlement mechanisms of larval stone flounder, Kareius bicoloratus, into nursery grounds. Fish Oceanogr 5:194-204 